\begin{tabular}{cc|c}
\hline Tar. Bil. Der. & Journal of Agricultural Sciences \\
& $\begin{array}{c}\text { Dergi web sayfası: } \\
\text { www.agri.ankara.edu.tr/dergi }\end{array}$ & Journal homepage: \\
& www.agri.ankara.edu.tr/journal
\end{tabular}

\title{
Sıcak Hava Kurutma Yönteminde Farklı Sıcaklık ve Ön İşlemlerin Trabzon Hurmasının Renk ve Kuruma Karakteristiklerine Etkisi
}

\author{
Yahya TÜLEK ${ }^{a}$, Engin DEMIRAY ${ }^{a}$ \\ ${ }^{a}$ Pamukkale Üniversitesi, Mühendislik Fakültesi, Glda Mühendisliği Bölümü, Kınıkl, 20020, Denizli, TÜRKIYE
}

\section{ESER BILLİSi}

Araştırma Makalesi — Tarım Teknolojileri DOI: 10.1501/Tarimbil_0000001262

Sorumlu Yazar: Yahya TÜLEK, E-posta: ytulek@pau.edu.tr, Tel: + 90 (258) 2963105

Geliş Tarihi: 29 Temmuz 2013, Düzeltmelerin Gelişi: 30 Ekim 2013, Kabul:06 Kasım 2013

\begin{abstract}
ÖZET
$\mathrm{Bu}$ çalışmada, Trabzon hurmalarının kabin tipi kurutma sisteminde, sıcak hava ile kurutulmasında üç farklı ortam sıcaklığının $\left(55,65\right.$ ve $\left.75^{\circ} \mathrm{C}\right)$ ve ön işlem olarak uygulanan \% 20'lik sakkaroz çözeltisinde ozmotik ön kurutma işlemi ile $80^{\circ} \mathrm{C}$ su içerisinde 15 dakika bekletme işlemlerinin renk özelliklerine ve kuruma karakteristiklerine etkisi araştırılmıştır. $80^{\circ} \mathrm{C}$ su içerisinde yapılan bekletme işleminin ozmotik ön kurutma işlemine göre renk karakteristikleri üzerine daha olumlu etki yaptığı, bununla birlikte, ozmotik ön kurutmaya tabi tutulan örneklerin kuruma sürelerinin daha kısa olduğu saptanmıştır. Kurutma ortam sıcaklığındaki artışın kuruma sürelerini belirgin şekilde azalttığı fakat yüksek sıcaklıkların renk karakteristiklerinin kötüleşmesine neden olduğu belirlenmiştir. Her bir kurutma işleminde renk karakteristiklerindeki değişimlerin birinci dereceden kinetik modele uygun gerçekleştiği de tespit edilmiştir.
\end{abstract}

Anahtar Kelimeler: Trabzon hurması; Kurutma; Sıcak hava; Ön işlem; Renk

\section{Effect of Hot Air Drying and Different Pretreatments on Color and Drying Characteristics of Persimmons}

\section{ARTICLE INFO}

Research Article - Agricultural Technologies

Corresponding Author: Yahya TÜLEK, E-mail: ytulek@pau.edu.tr, Tel: + 90 (258) 2963105

Received: 29 July 2013, Received in Revised Form: 30 October 2013, Accepted: 06 November 2013

\begin{abstract}
In this study, the effect of different pretreatments and three drying temperature $\left(55,65\right.$ and $\left.75{ }^{\circ} \mathrm{C}\right)$ on the hot air drying characteristics and color of persimmon were investigated. As pretreatments, persimmons were immersed in $20 \%$ sucrose solution or dipped in water at $80^{\circ} \mathrm{C}$ for 15 minutes. As a result, it was determined that dipped in water at $80^{\circ} \mathrm{C}$ pretreatment was better than immersed in $20 \%$ sucrose solution pretreatment on the color characteristics of persimmons. However pretreatments, which immersed in $20 \%$ sucrose solution, decreased the drying time. A significant reduction of the increase in drying times ambient temperature, but the high temperatures caused by deterioration of the color characteristics were determined. Changes in the characteristics of each color in a drying process takes place in accordance with the first-order kinetic model were determined. Keywords: Persimmons; Drying; Hot air; Pretreatment; Color
\end{abstract}




\section{Giriş}

Trabzon hurmasının anavatanı Çin olup (Luo 2006), ülkemizde özellikle Akdeniz bölgesinde yoğun olarak yetiştirilmektedir (Karkacier 1998; Doymaz 2012). Trabzon hurması (Diospyros kaki), sistematik olarak Ebenales takımı, Ebenaceae familyası ve Diospyros cinsi içerisinde yer almaktadır (Yıldız 2011). Diospyros türleri Asya, Afrika, Avustralya, Güney ve Kuzey Amerika kitalarının subtropik ve tropik alanlarında doğal olarak bulunmaktadır (Yonemori et al 2000). Diospyros cinsi içerisinde yalnızca 4 türün ticari olarak meyve üretiminde kullanıldığı, bunların Diospyros kaki Thun., Diospyros lotus L., Diospyros virginiana L. ve Diospyros oleifera Cheng olduğu Kitagawa \& Glucina (1984) tarafından bildirilmiştir (Yıldız 2011).

Diospyros adı Yunancada "Dios" (Baştanrı, Jupiter) ve "pyros" (tane) kelimelerinin birleşmesi ile meydana gelmiş olan "kutsal yiyecek" ya da "tanrıların yiyeceği”, anlamına gelmektedir. Meyvelerinin görünümlerinin güzelliği ve tatlarının mükemmelliğinden dolayı bu ismi almıştır (Onur 1990; Y1ldız 2011). Dünyanın büyük bir bölümünde 'Kaki' diye, Amerika'da ise 'Persimmon' olarak adlandırılır. Türkiye'nin değişik bölgelerinde "Hurma", "Cennet meyvesi", "Japon elması" ve "Amme" olarak adlandirilan Trabzon hurması, daha çok üretim bölgelerinde tanınmakta ve tüketilmektedir (Onur 1985).

Trabzon hurması, ağacının bakımının kolay olması, az masrafla yetiştirilmesi ve yüksek oranda geliri dolayısıyla, avantajlı bir türdür. İçerdiği çeşitli mineral maddeler, vitaminler (özellikle yüksek oranda $\mathrm{A}$ ve $\mathrm{C}$ vitaminleri) ve kendine özgü bir tat ve aroması olması sebebiyle tüketici açısından da tercih edilen bir meyvedir. Ayrıca üstün kalitede reçel ve marmelat yapımında, dondurma ve pastalarda kullanılması, dondurularak veya kurutularak muhafaza edilebilmesi ve değişik şekillerde işlenerek gida endüstrisi için çok değerli bir hammadde olabilme niteliklerine sahiptir (Sütyemez \& Ergenoğlu 2000).

Meyve ve sebzelerin bozulmadan ve kalitesini koruyarak uzun süre saklanabilmeleri için uygulanan yöntemlerden birisi olan kurutma, en eski ve uygulama alanı en geniş olan yöntemdir. Meyve ve sebzelerin soğutularak, dondurularak, kimyasal maddelerle işlemlerden geçirilerek, oksijensiz ortamda depolanarak, ultraviyole ve radyoaktif 1şınlardan yararlanmak suretiyle uzun süre saklanması mümkün olmakla birlikte bu uygulamalar içerisinde kendine en geniş uygulama alanı bulan yöntem kurutmadır (Yağcıŏlu 1996; Mutlu \& Ergüneş 2008).

Meyve ve sebzelerin kurutulmasının nedeni yalnızca bozulmadan uzun süre saklanabilmelerini sağlamaya yönelik değildir. Aynı zamanda kurutma uygulaması ile meyve ve sebzelerin ağırlık ve bazen de hacimsel azalmalarına paralel olarak, taşıma, depolama, paketleme maliyetlerinde önemli avantajlar sağlanmaktadır. Ayrıca, bu ürünlerin diğer kuru ürünlerle karışımı çok kolay olduğu için kullanım alanları da çok geniştir. Kurutulmuş sebzeler genellikle hazır çorba ve sos karışımları ile hazır yemeklerde kullanılırken, kurutulmuş meyvelerde, keklerde, puding karışımlarında bisküvi ve tartlarda düşük maliyetli katkılar olarak geniş çapta kullanılmaktadır (Holdsworth 1986; İspir 2006).

Meyve ve sebzelerin kurutulması bu ürünlerin kalitesini olumsuz etkileyebilmektedir. Özellikle yüksek sıcaklıkta hava ile kurutulmuş ürünlerin tekrar su alma yani rehidrasyon özelliği azalmakta, isısal bozulma nedeni ile renk, doku ve lezzetinde arzu edilmeyen değişmeler meydana gelebilmektedir. Ayrıca besin öğelerinin de bir kısım kayba uğradığı bilimsel çalışmalarla belirlenmiştir (İspir 2006). Bu nedenle, kurutma yöntemleri üzerine çok sayıda araştırma yapılmıştır ve yapılmaktadır. Araştırılan yöntemler içerisinde en iyi kalitede ürünün dondurulmuş halde kurutma tekniği ile elde edildiği kabul edilmesine rağmen bu yöntemin oldukça pahalı olduğu da bilinmektedir (Krokida \& Maroulis 2000).

Kurutma tekniğinin geliştirilmesi üzerine yapılan çalışmalarda, son ürünün kalitesine kurutma öncesi uygulanan ön işlemlerin de önemli etkileri olduğu ortaya çıkmıştır. $\mathrm{Bu}$ doğrultuda 
son yıllarda, ozmotik kurutmanın bir ön işlem olarak uygulanması ile ilgili araștırmalarda da önemli bir artış olmuştur. Ozmotik kurutma, hipertonik (ozmotik) bir çözeltiye daldırılmış bitki dokularından suyun kısmen uzaklaştırılmasıdır. Dokulardan çözelti içerisine suyun difüzyonu, doku ve hipertonik çözelti arasındaki ozmotik basınç tarafından yürütülmektedir. Su difüzyonuna, katının doku içerisinden aynı anda zıt difüzyonu eşlik etmektedir. Ozmotik taşınmada rol oynayan hücre zarı tam olarak seçici olmadığından, hücre içinde bulunan diğer katıların da ozmotik çözelti içerisine geçmesi söz konusu olabilir (Rastogi et al 2000). Daldırma ile katı kazanımı ve su kaybı olarak da bilinen ozmotik kurutmanın diğer kurutma işlemleri ile karşılaştırıldığında, farklı olan özelliği gıdanın içine ozmotik çözelti içerisindeki katıların işlem süresince nüfuz etmesidir. $\mathrm{Bu}$ şekilde gıda maddesinin bileşiminin değişmesi ile gıdanın sonradan uygulanacak işlemler için daha uygun bir hale gelmesi de mümkün olabilmektedir (Torreggiani \& Bertolo 2001).

Yurdumuzda son yıllarda, özellikle Ege Bölgesinde üretim potansiyelinde önemli düzeylerde artış görülen Trabzon hurmasının tüketimi genellikle taze olarak yapılmasına rağmen, kurutularak mevsim dışında da tüketilebilmesine yönelik çalışmalara başlandığı tarafımızca da görülmüştür. Carcel ve arkadaşları (2007) yaptıkları bir çalışmada, Trabzon hurmalarını $30 \mathrm{~mm}$ kalınlığında ve $13 \mathrm{~mm}$ çapında dilimledikten sonra dilimleri iki partiye ayırmışlardır. İlk parti yüksek yoğunluklu ultrases dalga destekli sicak havalı kurutucuda, diğer parti ise ultrases dalga desteği olmadan kurutulmuştur. Sonuç olarak ultrases dalga desteği ile kurutulan Trabzon hurma dilimlerinin daha hızlı kuruduğu belirlenmiştir (Carcel et al 2007). Yapılan bir başka çalışmada, yerel bir marketten satın alınan aynı boyut ve turuncu renkteki Trabzon hurmaları laboratuara getirildikten sonra teker teker yıkanıp kabukları elle soyulmuştur. Soyulmuş bütün haldeki Trabzon hurmaları tepsili kurutucuya yerleştirilmiştir. 40 ile $70^{\circ} \mathrm{C}$ arasında değişen hava sıcaklıklarında ve 0.8 ile $2 \mathrm{~m} / \mathrm{s}$ değerleri arasında değişen hava hızlarında kurutma işlemleri gerçekleştirilmiştir. Kurutma sonunda, meyvelerin C vitamini değerlerinin kurutma sicaklığının artmasıyla azaldığ 1 belirlenmiştir (Nicoleti et al 2007). Doymaz (2012), yaptığı çalışmada Trabzon hurmalarını yıkadıktan sonra kabuklarını soymuş ve $5 \mathrm{~mm}$ kalınlıkta olacak şekilde dilimlemiştir. Dilimleri iki partiye ayırdıktan sonra birinci partiyi $70^{\circ} \mathrm{C}$ 'deki suda 2 dakika boyunca haşlamıştır. Diğer partiye ise herhangi bir ön işlem uygulamamıştır. Üç farklı sıcaklıkta $\left(50{ }^{\circ} \mathrm{C}, 60{ }^{\circ} \mathrm{C}\right.$ ve $\left.70{ }^{\circ} \mathrm{C}\right)$ sicak havalı kurutucuda partileri sırasıyla kurutmuştur. Kurutma işlemleri sonunda ön işlem uygulanmış dilimlerin diğerlerine göre daha hızlı kuruduğunu ifade etmiştir. Yaptığımız çalışmalarla ve literatür taramaları sonucunda bu meyvenin henüz endüstriyel anlamda kurutmasının yapılmadığı, kurutmada uygulanabilecek yöntem ve koşulların henüz tanımlanmamış olduğu saptanmıştır. $\mathrm{Bu}$ nedenle, bu çalışma ile Trabzon hurmasının, birçok meyve ve sebzenin kurutulmasında en yaygın olarak kullanılan sıcak hava kurutma yöntemi ile kurutulması gerçekleştirilerek, uygulanan farklı ortam sicaklıklarının ve kurutma öncesi uygulanan ön işlemlerin meyvelerin kuruma karakteristikleri ile renk özelliklerine etkisinin belirlenmesi, sonuçta endüstriyel anlamda kullanılabilecek şartların tanımlanması amaçlanmıştır.

\section{Materyal ve Yöntem}

\subsection{Materyal}

Bu çalışmada, Türkiye'de üretimi yapılan kurutma işlemine uygun Trabzon hurması çeşitlerinden biri olan Diospyros cinsi materyal olarak seçilmiştir. Kurutma denemelerinde kullanilacak olan Diospyros cinsi Trabzon hurmaları Ekim ayının ortasından itibaren Denizli ili Honaz ilçesinden direkt üreticiden temin edilmiş olup, $5.5-6 \mathrm{~cm}$ çapında ve $6-6.2 \mathrm{~cm}$ uzunluğundadır. Trabzon hurmaları, kurutma denemelerinde kullanılıncaya kadar polietilen ambalaj içerisinde buzdolabı koşullarında muhafaza edilmiştir. 


\subsection{Yöntem}

\subsubsection{Kurutma sistemi}

Trabzon hurmaları, Yücebaş Makine Tic. Ltd. Şti. (İzmir) tarafından üretilip, bölüm laboratuarına kurulan kabin tipi kurutuca kurutulmuştur. Kurutma kabininin genel görünümü Şekil 1'de ve kurutma kabinine ait teknik özellikler Çizelge 1'de verilmiştir.

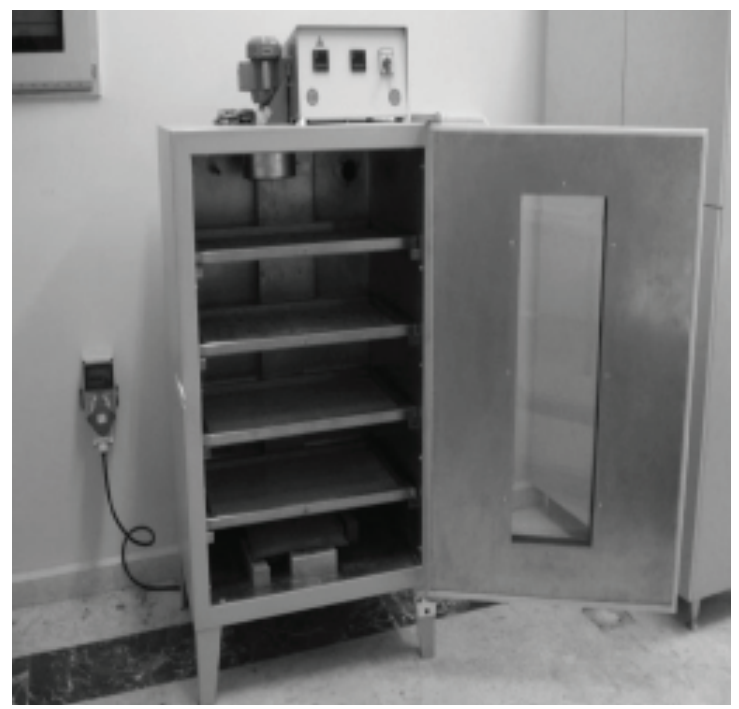

Şekil 1- Kurutma kabininin genel görünümü

Figure 1- The general view of cabinet dryer

\section{Çizelge 1- Kurutma kabininin teknik özellikleri}

Table 1- The technical properties of cabinet dryer

\begin{tabular}{ll}
\hline Özellikler & Değerler \\
\hline Dış genişlik & $80 \mathrm{~cm}$ \\
Dış derinlik & $60 \mathrm{~cm}$ \\
Dış yükseklik & $110 \mathrm{~cm}$ \\
Kabin iç boyutları & $70 \times 55 \times 100 \mathrm{~cm}$ \\
Çalışabilir sıcaklık aralığı & $40^{\circ} \mathrm{C}-120^{\circ} \mathrm{C}$ \\
Çalışabilir bağıl nem (RH) & $\% 20-\% 95$ \\
aralı̆ı & \\
Çalışabilir hava hızı aralığı & $0-2 \mathrm{~m} \mathrm{~s}^{-1}$ \\
Programlama & Kabin içindeki sıcaklık ve \\
& bağıl nem dijital olarak \\
& ayarlanır ve izlenebilir. \\
& $40 x 60 \mathrm{~cm}$ ebadında, delikli \\
Tepsi özellikleri & paslanmaz çelik telden elek \\
& şeklinde yapılmışs sabit \\
& olmayan 4 adet tepsi \\
\hline
\end{tabular}

\subsubsection{Kuru madde tayini}

Örneklerinkurumaddemiktarlarınınbelirlenmesinde AOAC, 920.151 yöntemi uygulanmıştır.

\subsubsection{Renk tayini}

Kurutma işleminin Trabzon hurması numunelerinin renk değişimi üzerindeki etkisini incelemek için yapılan çalışmada; kurutma süresince önceden belirlenen zaman aralıklarında numunelerin renk değerleri, renk ölçüm cihazı ile ölçülmüştür. Renk ölçümleri gerçekleştirilmeden önce Hunterlab MiniScan XE renk ölçüm cihazı beyaz ve siyah standart kalibrasyon plakaları ile kalibre edilmiştir. Renk ölçümleri, 3 farklı noktadan yapılmış ve elde edilen değerlerin ortalamaları alınarak değerlendirilmiştir. Burada "L" değeri parlaklığı, "+a" değeri kırmızılığ ve "+b" değeri ise sarılı̆̆ ifade eder (Doymaz \& Pala 2001).

\subsubsection{Su aktivitesi tayini}

Taze ve kurutulmuş haldeki Trabzon Hurması örneklerinin su aktiviteleri \pm 0.001 hassasiyete sahip su aktivitesi ölçüm seti (Testo-AG 650) kullanılarak belirlenmiştir. $\mathrm{Bu}$ amaçla yaklaşık 3-4 gram parçalanmış örnek hızlı bir şekilde aletin paslanmaz çelikten yapılmış sızdırmaz haznesine yerleştirilmiştir. Su aktivitesi değerinde, 10 dakika boyunca 0.001 'den az bir değişim olduğunda sistemin dengeye ulaştığ 1 kabul edilmiş ve cihazın göstergesinden su aktivitesi değeri doğrudan okunmuştur (Hastürk et al 2012).

\subsubsection{Kurutma işleminden önce yapılan ön işlemler ve kurutma}

Kurutma işleminde kullanılacak olan Trabzon hurmalarının aynı olgunluk derecesinde ve standart boyutta olmasına dikkat edilerek üreticiden alınıp, polietilen poşetler içerisinde bölüm laboratuarına getirilmiş ve 1500 gramlık partilere ayrılarak yine polietilen poşetler içerisinde, denemelerde kullanılıncaya kadar buzdolabı koşullarında muhafaza edilmiştir.

Her bir kurutma denemesinde 15 adet örnek kullanılmıştır. $\mathrm{Bu}$ örneklerden 8 adedi $20{ }^{\circ} \mathrm{C}$ sıcaklıkta, \% 20’lik sakkaroz çözeltisinde Şekil 
2'de gösterildiği gibi, geri kalan 7 adet numune de $80{ }^{\circ} \mathrm{C}$ 'deki su içerisinde 15 dakika bekletilmiştir. Çalışmanın detayları aşağıdaki gibi verilmiştir.

Kurutma denemelerinde kullanılan 3 ayrı sicaklığın $\left(55^{\circ} \mathrm{C}, 65{ }^{\circ} \mathrm{C}, 75^{\circ} \mathrm{C}\right)$ her biri için 1500 gram Trabzon hurması ayrılmıştır. $\mathrm{Bu} 1500$ gramın şeker çözeltisine daldırılan yaklaşık 800 gramlık örneğinden bir tanesi sicak su içerisinde bekletilmiş, geri kalan 700 gramlık örneğin de yine bir tanesi kurutma sırasında belli zaman aralıkları (genellikle 1'er saat) ile ağırlık kaybını takip etmek ve renk değerlerindeki değişimi belirlemek için kullanılmıştır. Kurutma işlemi, Trabzon hurmalarında su oranı yaklaşık \% 35'e ulaşılınca tamamlanmıştır. Kurutma, tüm sicaklıklar için 0.2 $\mathrm{m} \mathrm{s}^{-1}$ sabit hava hızında ve \% 20 sabit bağıl nem ortamlarında gerçekleştirilmiştir.

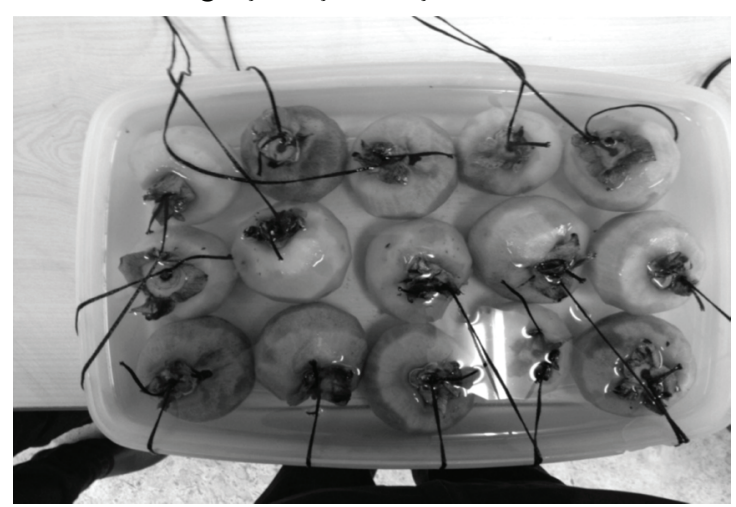

Şekil 2- Şeker çözeltisine (\% 20’lik) daldırılan Trabzon hurmaları

Figure 2- Persimmons immersed in a $20 \%$ sugar solution

Sap1 koparılmamış Trabzon hurmalarının öncelikle kabukları soyulmuştur. Bu işlem dikkatli bir şekilde gerçekleştirilerek Trabzon hurmalarının zedelenmemesine özen gösterilmiştir. Trabzon hurmaları saplarından, eşit uzunluklarda önceden hazırlanmış olan iplerle bağlanmıştır. 15'er adet olacak şekilde hazırlanan partilerin ve ağırlık kaybını ve renk değişimini belirlemek için takibe alınacak olan takip numunelerinin ilk ağırlıkları tartılarak not edilmiştir. Partilerden biri sıcak suda 15 dakika bekletilirken, diğer parti ise şeker çözeltisinde 15 dakika bekletilmiştir. Şeker çözeltisi \% 20 şeker içerecek şekilde $20{ }^{\circ} \mathrm{C}$ sıcaklıkta hazırlanmıştır. Sıcak suya ve şeker çözeltisine daldırılan örnekler daldırma sonrası yüzeydeki suların uzaklaşması için bir dakika kadar oda sıcaklığında bekletilmiştir. Tartım ve renk ölçümleri için takibe alınan iki numune de bu işlemlerden sonra ağırlıkları tekrar tartılıp, renk değerleri ölçülmüştür. Daha sonra uçları çengellere bağlanmış iplerle, kurutma kabinin içine sığacak şekilde hazırlanmış olan taşınabilen ızgaraya homojen bir dağılımla asılarak yerleştirilmişlerdir. Kurutma denemelerine başlamadan yaklaşık 1 saat öncesinde kurutma sistemi çalıştırılmış ve sistemin rejime gelmesi sağlandıktan sonra örnekler kabine yerleştirilmiştir. Şekil 3'de kurutma kabinindeki ön işlem görmüş Trabzon hurmaları görülmektedir. İki farklı ön işlem uygulanarak ve üç farklı sıcaklıkta kurutulmuş Trabzon hurmaları raf ömürlerini belirlemek amaciyla polietilen poşetler içerisinde oda koşullarda muhafaza edilmiş ve mikrobiyal yönden (küflenme) bozulma takibi yapılmıştır. Tüm bu işlemler 2 tekerrürlü ve 2 paralelli olacak şekilde gerçekleştirilmiştir.

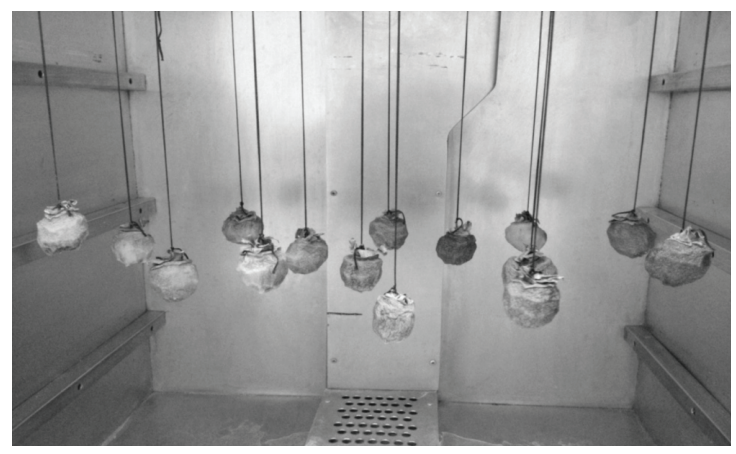

Şekil 3- Kurutma kabinindeki ön işlem görmüş Trabzon hurmaları

Figure 3- Pretreated persimmons in cabinet dryer

\subsubsection{Duyusal değerlendirme}

Yüzde yirmilik (\% 20) şeker çözeltisine ve $80^{\circ} \mathrm{C}^{\prime}$ lik suya daldırıldıktan sonra kurutulan Trabzon hurmaları duyusal değerlendirmeye tabi tutulmuştur. Duyusal analiz testinde 32 kişilik panelist grubu kullanılmıştır. Panelist olarak Pamukkale Üniversitesi, Mühendislik Fakültesi öğrencileri ve öğretim elemanları görev 
almıştır. Panelistler, Trabzon hurmalarını koku, lezzet, renk, çiğnenebilirlik ve genel beğeni açısından hedonik skalada aşırı kötüden mükemmele; 1'den 7 puana kadar olan aralıkta değerlendirmiştir. Değerlendirmeye alınan kurutulmuş Trabzon hurma özelliklerine ait puanlar ayrı ayrı toplanmış ve panelist sayısına bölünmüştür. Skalalar her iki örnek açısından karşılaştırılarak, kıyaslamaya tabi tutulmuştur.

\subsection{Hesaplamalar}

Trabzon hurması numunelerinin sicak hava ile kabin tipi kurutucuda kurutulması sırasında meydana gelen renk değişiminin incelenmesinde renk ölçüm cihazı ile belirlenen Hunter L, a, b değerleri kullanılarak reaksiyon dereceleri belirlenmiştir.

\subsubsection{Renk değişimlerinin incelenmesi için yapılan modelleme çalışmaları}

Sifirıncl dereceden kinetik model: Sifirınc1 dereceden kinetik model aşağıda sunulmuştur.

$C=C_{0} \pm k t$

Birinci dereceden kinetik model: Birinci dereceden kinetik model aşağıda sunulmuştur.

$C=C_{0} \exp ( \pm k t)$

Sifirınc1 ve birinci dereceden kinetik modele ait bu denklemlerde $(+)$ ve $(-)$ bozunma ve oluşma reaksiyonlarını temsil etmektedir.

Aktivasyon enerjisinin hesaplanmast: Reaksiyonun sıcaklık derecesine bağımlılık düzeyi, aktivasyon enerjisinin $\left(\mathrm{E}_{\mathrm{a}}\right)$ hesaplanmasıyla belirlenmiştir. Reaksiyon hızı ve sıcaklık arasındaki ilişki Arrhenius tarafından $1889^{\prime}$ da tanımlanmış olup, ifade aşağıda verilmişstir.

$k=k_{0} \exp ^{-E a / R T}$

\section{Bulgular ve Tartışma}

\subsection{Nem içeriği değişimi}

Çalışmada kullanılan Trabzon hurması numunelerinin başlangıç ortalama nem içeriği $3.30 \mathrm{~g}$ su g kuru madde ${ }^{-1}$, su aktivitesi de 0.92 olarak bulunmuştur. İki farklı ön işlem ve üç farklı kurutma sıcaklığında kurutulan Trabzon hurması örneklerinin zamana bağlı olarak nem içeriğindeki değişimler Şekil 4 ve 5'de verilmiştir.

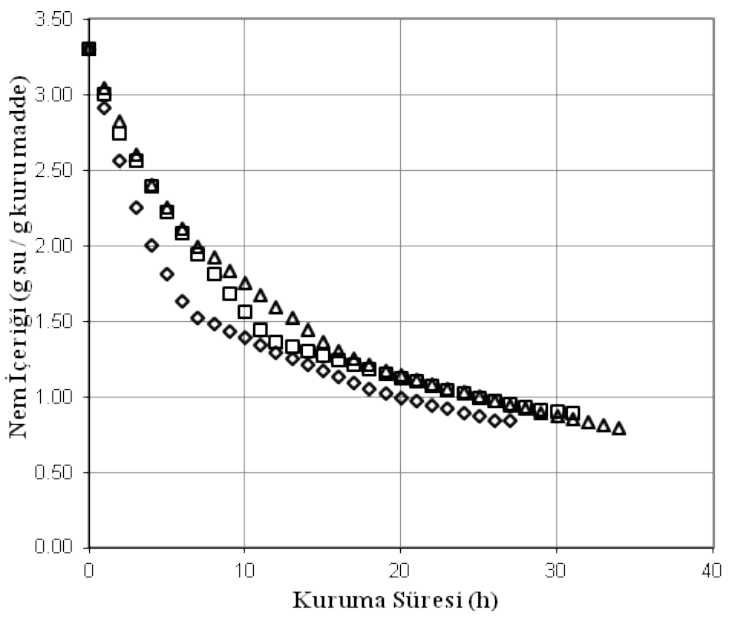

Şekil 4-80 ${ }^{\circ} \mathrm{C}^{\prime}$ deki suya daldırıldıktan sonra kurutulan numunelere ait nem içeriği değerlerinin kuruma zamanı ile değişimi: $\triangle, 55^{\circ} \mathrm{C}$; $\square, \mathbf{6 5}^{\circ} \mathrm{C} ; \diamond, 75^{\circ} \mathrm{C}$

Figure 4- The changing of the immersed in water at $80^{\circ} \mathrm{C}$ after dried samples moisture content values and drying time: $\triangle, 55^{\circ} \mathrm{C} ; \square, 65{ }^{\circ} \mathrm{C} ; \diamond, 75^{\circ} \mathrm{C}$

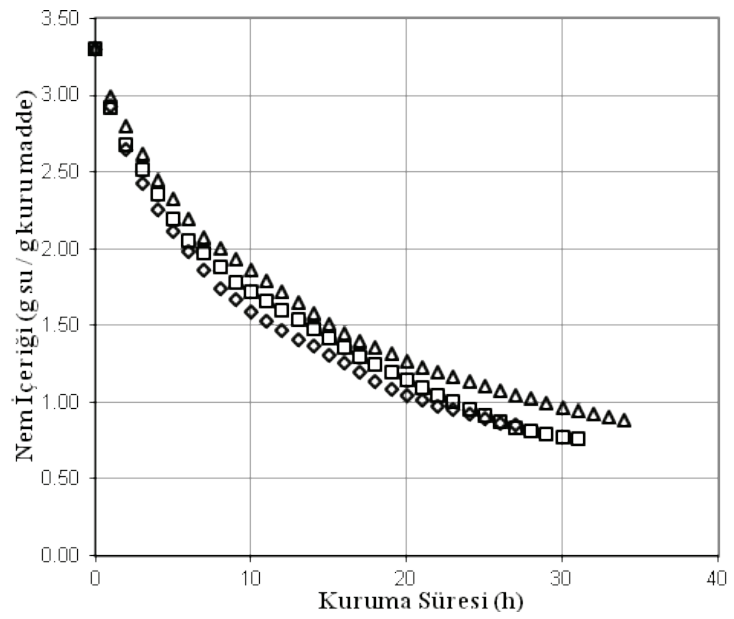

Şekil 5- Şeker çözeltisine (\% 20’lik) daldırıldıktan sonra kurutulan numunelere ait nem içeriği değerlerinin kuruma zamanı ile değişimi: $\triangle, 5^{\circ} \mathrm{C}$; $\square, 65^{\circ} \mathrm{C} ; \diamond, 75^{\circ} \mathrm{C}$

Figure 5- The changing of the immersed in 20\% sucrose solution after dried samples moisture content values and drying time: $\triangle, 55^{\circ} \mathrm{C}$; $\square, 65^{\circ} \mathrm{C} ; \diamond, 75^{\circ} \mathrm{C}$ 
Kurutma havası sıcaklığının $55^{\circ} \mathrm{C}$ 'den $75^{\circ} \mathrm{C}$ 'ye yükseltilmesi ile şeker çözeltisine daldırıldıktan sonra kurutulan numunelerde toplam kurutma sürelerinde $\% 21$ oranında azalma tespit edilmiştir. Kurutma havası sıcaklığının yükselmesiyle hem difüzyon hem de kütle transferinin hızlandığı bilinmektedir (Kaya 2008). Bu etkiler, ürünün daha çabuk kurumasına sebep olmaktadır. Bunun dışında şeker çözeltisine daldırıldıktan sonra kurutulan Trabzon hurmalarının, sicak suda bekletildikten sonra kurutulanlara göre yaklaşık 3 saat daha kısa sürede kuruduğu belirlenmiştir.

Literatürdeki bazı çalışmalar incelendiğinde de ön işlem uygulanarak kurutulan Trabzon hurmalarının, ön işlem yapılmadan kurutulanlara göre daha kısa sürede kuruduğu görülmüştür (Carcel et al 2007; Doymaz 2012) Ayrica C vitaminin de ön işlem uygulanarak kurutulan numunelerde daha az kayba uğradığı belirtilmiştir (Nicoleti et al 2007).

\subsection{Farklı sıcaklık değerlerinde yapılan kurutma işleminin Trabzon hurması numunesinin renk değişimi üzerindeki etkisi}

Kurutma kabininde konvektif olarak kurutulan Trabzon hurmalarının kurutma işleminde zamana bağlı olarak renk değişimleri belirlenmiştir. Yapılan modelleme çalışmaları sonucunda Hunter L, a ve $b$ değerlerinin birinci dereceden kinetik modele uygunluk gösterdiği görülmüştür. Farklı sicaklık değerleri için elde edilen Hunter L, a, b değerlerindeki değişimler Şekil 6-11'de, matematiksel model sabitleri ve istatistik veriler Çizelge 2 ve 3 'de verilmiştir.

Çizelge 2- Şeker çözeltisine (\% 20'lik) daldırılmış örneklerin sıcak hava ile kurutmasında renk değişim kinetik parametreleri

Table 2- Kinetic parameters of color degradation during hot air drying (immersed in 20\% sucrose solution)

\begin{tabular}{|c|c|c|c|c|c|c|}
\hline \multirow{2}{*}{ Parametre } & \multirow{2}{*}{ Reaksiyon derecesi (n) } & \multirow{2}{*}{ Sicaklık $\left({ }^{\circ} \mathrm{C}\right)$} & \multirow{2}{*}{$\begin{array}{c}k \\
\left(h^{-1}\right)\end{array}$} & \multirow{2}{*}{$R^{2}$} & \multicolumn{2}{|c|}{ Arrhenius eşitliği } \\
\hline & & & & & $E_{a}\left(\mathrm{~kJ} \mathrm{~mol}^{-1}\right)$ & $R^{2}$ \\
\hline \multirow{3}{*}{$L$} & \multirow{3}{*}{1} & 55 & 0.0028 & 0.9286 & \multirow{3}{*}{49.30} & \multirow{3}{*}{0.9911} \\
\hline & & 65 & 0.0052 & 0.9962 & & \\
\hline & & 75 & 0.0079 & 0.9516 & & \\
\hline \multirow{3}{*}{$a$} & \multirow{3}{*}{1} & 55 & 0.0021 & 0.9817 & \multirow{3}{*}{58.94} & \multirow{3}{*}{0.9699} \\
\hline & & 65 & 0.0033 & 0.9210 & & \\
\hline & & 75 & 0.0073 & 0.9684 & & \\
\hline \multirow{3}{*}{$b$} & \multirow{3}{*}{1} & 55 & 0.0013 & 0.9885 & \multirow{3}{*}{96.24} & \multirow{3}{*}{0.9458} \\
\hline & & 65 & 0.0056 & 0.9100 & & \\
\hline & & 75 & 0.0098 & 0.9852 & & \\
\hline
\end{tabular}

Çizelge 3- $80{ }^{\circ} \mathrm{C}^{\prime}$ deki suya daldırılmış örneklerin sıcak hava ile kurutmasında renk değişim kinetik parametreleri

Table 3- Kinetic parameters of color degradation during hot air drying (dipped in hot water at $80^{\circ} \mathrm{C}$ )

\begin{tabular}{|c|c|c|c|c|c|c|}
\hline \multirow{2}{*}{ Parametre } & \multirow{2}{*}{ Reaksiyon derecesi (n) } & \multirow{2}{*}{$\operatorname{Sicakllk}\left({ }^{\circ} \mathrm{C}\right)$} & \multirow{2}{*}{$\begin{array}{c}k \\
\left(h^{-1}\right)\end{array}$} & \multirow{2}{*}{$R^{2}$} & \multicolumn{2}{|c|}{ Arrhenius eşitliği } \\
\hline & & & & & $E_{a}\left(\mathrm{~kJ} \mathrm{~mol}^{-1}\right)$ & $R^{2}$ \\
\hline \multirow{3}{*}{$L$} & \multirow{3}{*}{1} & 55 & 0.0024 & 0.8963 & \multirow{3}{*}{54.39} & \multirow{3}{*}{0.8916} \\
\hline & & 65 & 0.0061 & 0.9926 & & \\
\hline & & 75 & 0.0075 & 0.9948 & & \\
\hline \multirow{3}{*}{$a$} & \multirow{3}{*}{1} & 55 & 0.0018 & 0.9627 & \multirow{3}{*}{56.62} & \multirow{3}{*}{0.9198} \\
\hline & & 65 & 0.0045 & 0.9511 & & \\
\hline & & 75 & 0.0059 & 0.9885 & & \\
\hline \multirow{3}{*}{$b$} & \multirow{3}{*}{1} & 55 & 0.0011 & 0.9781 & \multirow{3}{*}{98.43} & \multirow{3}{*}{0.9689} \\
\hline & & 65 & 0.0044 & 0.9592 & & \\
\hline & & 75 & 0.0087 & 0.9958 & & \\
\hline
\end{tabular}


Carcel et al (2010) yaptıkları bir çalışmada, Trabzon hurmalarını dilimledikten sonra bazı daldırma çözeltilerine daldırmışlar ve sonra tepsili bir kurutucuda kurutmuşlardır. Araştırıcılar kuruma süresince belli zaman aralıklarında ölçüm yapmayıp, sadece kurutma işleminin başında ve sonunda renk değerlerini belirlemişlerdir. Kurutulan örneklerin depolama süresince belli zaman aralıklarında renk değerleri ölçülmüş ve birinci dereceden kinetik modele uyduğu belirtilmiştir. Tarafımızdan yapılan çalışma reaksiyon derecesinin belirlenmesi yönüyle bu çalışmayla benzer gözükmekle birlikte, Carcel et al (2010) depolama sürecine ait renk değişim kinetiğini tanımlarken çalışmamızda kurutma sürecindeki renk değişim kinetiğinin tanımlanması amaçlanmıştır. $\mathrm{Bu}$ yönüyle değerlendirildiğinde, Trabzon hurmalarının kurutulmasıyla ilgili olarak çalışmamıza benzer çalışmaya literatürde rastlanmamıştır.

Şekil 6 ve 7'den de görüleceği üzere L değerlerinde zamana bağlı olarak belirgin bir azalma söz konusudur. Diğer taraftan L değerlerindeki bu azalmalar kurutma ortam sıcaklığındaki artışa bağlı olarak daha da artmıştır. Bu durum Trabzon hurmalarının renginin kurutma süresince zamana bağlı olarak giderek koyulaştığının, karardığının, yüksek sıcaklıklarda bu olayın daha da hızlı gerçekleştiğinin bir göstergesidir. Nitekim \% 20'lik şeker çözeltisine daldırılarak kurutulan Trabzon hurmalarında $55^{\circ} \mathrm{C}$ 'de 34 saat süre ile gerçekleştirilen kurutma sonucunda L değeri 46.32 değerine ulaşmış olmasına rağmen, 75 ${ }^{\circ} \mathrm{C}$ 'de ise 27 saatlik kurutma süreci sonunda L değeri 40.32'ye ulaşmıştır. $80{ }^{\circ} \mathrm{C}$ 'deki suya daldırılarak kurutulan Trabzon hurmalarında $55^{\circ} \mathrm{C}$ 'de 34 saat süre ile gerçekleştirilen kurutma sonucunda $\mathrm{L}$ değeri 48.27 değerine ulaşmış olmasına rağmen, $75^{\circ} \mathrm{C}$ 'de ise 27 saatlik kurutma süreci sonunda $\mathrm{L}$ değeri 43.28'ye ulaşmıştır.

Sicaklığa bağlı olarak renk değişiminde ortaya çıkan bu sonuç genel literatür verileri ile de uyumludur. Gıda maddelerinin yüksek sıcaklıklardaki ssıl işlem etkisine hassas olduğu, kalite kayıplarının sıcaklık artışına paralel olarak arttığı, gıdanın karakteristik rengini veren pigmentlerin isıl işlemlerden fazlaca etkilenerek önemli seviyelerde kayba uğradığı birçok araştırmacı tarafindan da ifade edilmiştir (Kerkhofs et al 2005; Alibaş 2012; Demiray et al 2013).

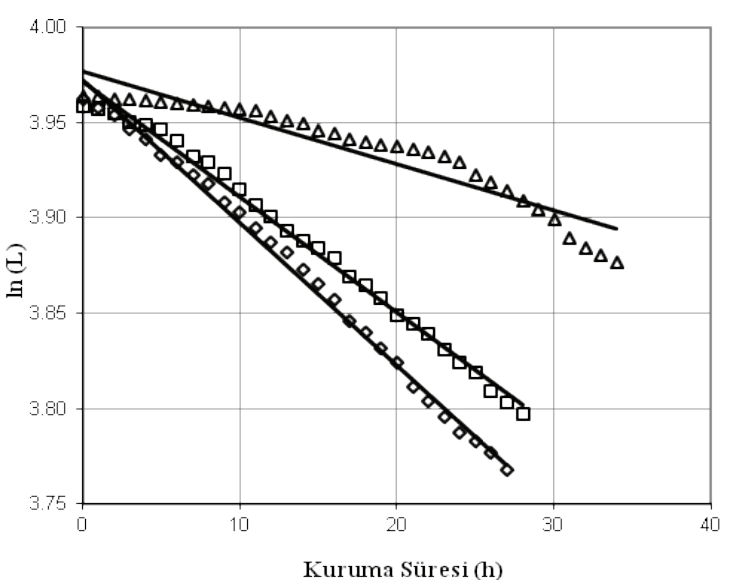

Şekil 6- $80{ }^{\circ} C^{\prime}$ deki suya daldırıldıktan sonra kurutulan numunelere ait $\mathrm{L}$ değerlerinin kuruma zamanı ile değişimi: $\triangle, 55^{\circ} \mathrm{C} ; \square, 65^{\circ} \mathrm{C} ; \diamond, 75^{\circ} \mathrm{C}$

Figure 6- The changing of the immersed in water at 80 ${ }^{\circ} \mathrm{C}$ after dried samples $L$ values and drying time: $\triangle, 55$ ${ }^{\circ} \mathrm{C} ; \square, 65^{\circ} \mathrm{C} ; \diamond, 75^{\circ} \mathrm{C}$

L değerinde olduğu gibi a değerinde de zamana bağlı olarak belirgin bir azalma saptanmıştır (Şekil 8 ve Şekil 9). Bu azalmalar kurutma ortam sıcaklığındaki artışa bağlı olarak daha da artmıştır. $\mathrm{Bu}$ durum Trabzon hurmalarının turuncu renginin kurutma süresince zamana bağlı olarak giderek koyulaştığının, kahverengi bir renk aldığının, yüksek sıcaklıklarda bu olayın daha da hızlı gerçekleştiğinin bir göstergesidir. Çizelge 2'de verilen reaksiyon hız sabitleri de incelendiğinde 75 ${ }^{\circ} \mathrm{C}$ 'de a değerindeki düşüşün $55^{\circ} \mathrm{C}$ 'ye göre 3.48 kat daha hızlı gerçekleştiği görülebilecektir.

$\mathrm{L}$ ve a değerlerinde olduğu gibi zamana bağlı olarak $b$ değerlerinde de belirgin bir azalma söz konusudur (Şekil 10 ve Şekil 11). Elde edilen veriler çerçevesinde, \% 20'lik şeker çözeltisine daldırılarak kurutulan Trabzon hurması örneklerinde belirlenen $\mathrm{L}$ değerlerinin çok az bir farkla da olsa, $80^{\circ} \mathrm{C}$ 'deki suya daldırılarak kurutulan örneklere göre daha düşük olduğu görülmüştür. $\mathrm{Bu}$ da, $80{ }^{\circ} \mathrm{C}$ 'deki suya daldırılıp kurutulan Trabzon hurmalarının, \% 20'lik şeker çözeltisine daldırılarak kurutulan Trabzon hurmalarına göre renginin daha açık ve parlak olduğunu göstermektedir. Buna karşılık, kırmızı 
rengin ölçüsü olan $+\mathrm{a}$ değerleri açısından örnekler karşılaştırıldığında, $\quad 80^{\circ} \mathrm{C}$ 'deki suya daldırılıp

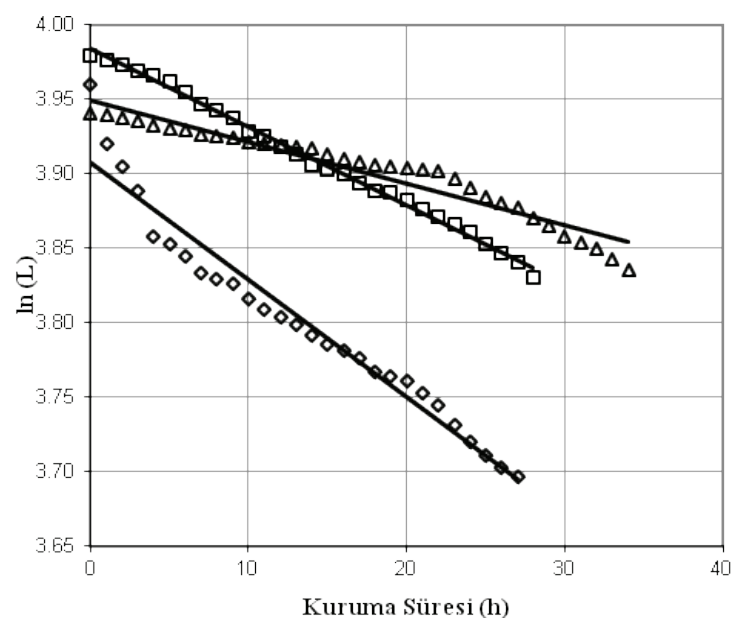

Şekil 7- Şeker çözeltisine (\% 20'lik) daldırıldıktan sonra kurutulan numunelere ait $\mathrm{L}$ değerlerinin kuruma zamanı ile değişimi: $\triangle, 5^{\circ} \mathrm{C}$; $\square, 6^{\circ} \mathrm{C} ; \diamond, 75^{\circ} \mathrm{C}$

Figure 7- The changing of the immersed in $20 \%$ sucrose solution after dried samples $L$ values and drying time: $\triangle 55^{\circ} \mathrm{C} ; \square, 65^{\circ} \mathrm{C} ; \diamond, 75^{\circ} \mathrm{C}$

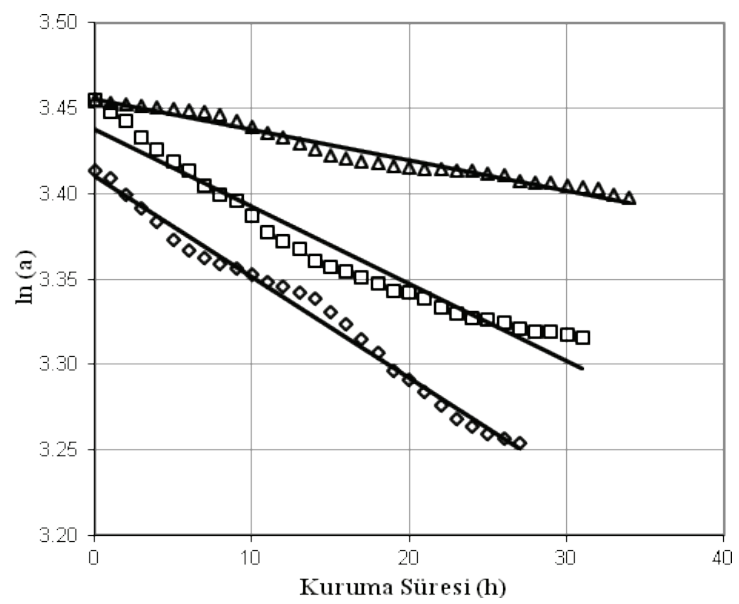

Şekil 8- $80{ }^{\circ} C^{\prime}$ deki suya daldırıldıktan sonra kurutulan numunelere ait a değerlerinin kuruma zamanı ile değişimi: $\triangle, 5^{\circ} \mathrm{C} ; \square, 6^{\circ} \mathrm{C} ; \diamond, 75^{\circ} \mathrm{C}$

Figure 8- The changing of the immersed in water at 80 ${ }^{\circ} \mathrm{C}$ after dried samples a values and drying time: $\triangle, 55$ ${ }^{\circ} \mathrm{C} ; \square, 65^{\circ} \mathrm{C} ; \diamond, 75^{\circ} \mathrm{C}$ kurutulan Trabzon hurmalarındaki kırmızılığın daha yoğun olduğu saptanmıştır.

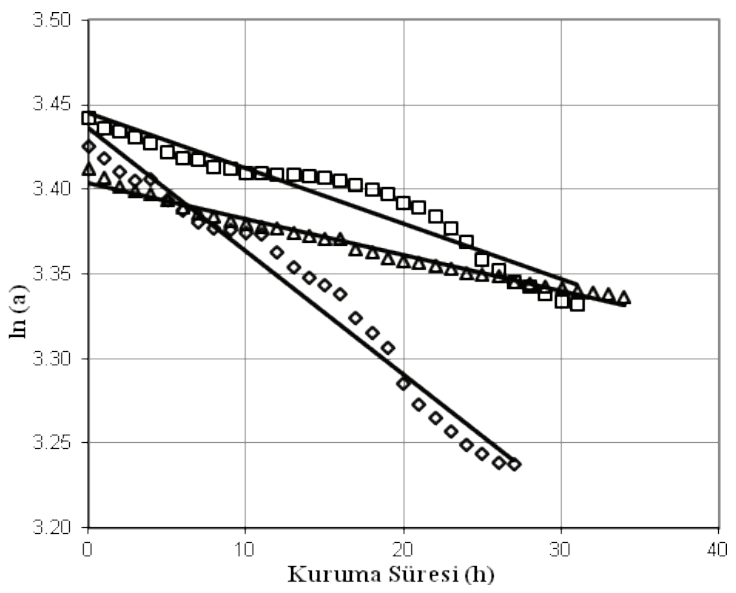

Şekil 9- Şeker çözeltisine (\% 20'lik) daldırıldıktan sonra kurutulan numunelere ait a değerlerinin kuruma zamanı ile değişimi: $\triangle, 55^{\circ} \mathrm{C}$; $\square, 65^{\circ} \mathrm{C}$; $\diamond$, $75^{\circ} \mathrm{C}$

Figure 9- The changing of the immersed in $20 \%$ sucrose solution after dried samples a values and drying time: $\triangle, 55^{\circ} \mathrm{C} ; \square, 65^{\circ} \mathrm{C} ; \diamond, 75^{\circ} \mathrm{C}$

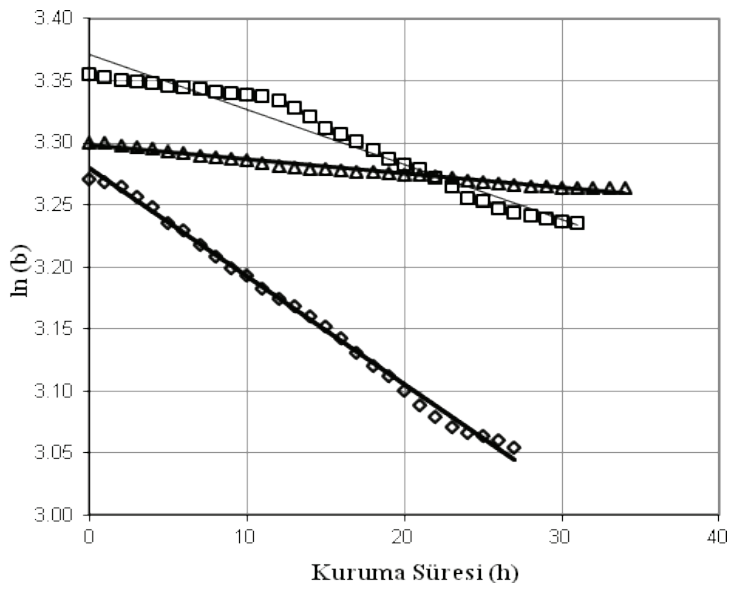

Şekil 10- $80{ }^{\circ} C^{\prime}$ deki suya daldırıldıktan sonra kurutulan numunelere ait $b$ değerlerinin kuruma zamanı ile değişimi: $\triangle, 5^{\circ} \mathrm{C} ; \square, \mathbf{6 5}^{\circ} \mathrm{C} ; \diamond, \mathbf{7 5}^{\circ} \mathrm{C}$

Figure 10- The changing of the immersed in water at $80^{\circ} \mathrm{C}$ after dried samples $b$ values and drying time: $\triangle$, $55^{\circ} \mathrm{C}$; $\square, 65^{\circ} \mathrm{C} ; \diamond, 75^{\circ} \mathrm{C}$ 


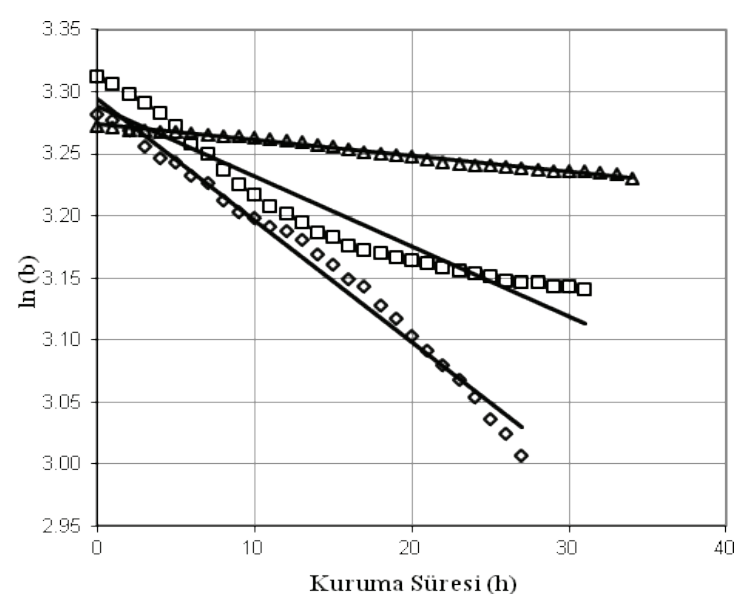

Şekil 11- Şeker çözeltisine (\% 20'lik) daldırıldıktan sonra kurutulan numunelere ait $b$ değerlerinin kuruma zamanı ile değişimi: $\triangle, 5^{\circ} \mathrm{C} ; \square, 65^{\circ} \mathrm{C} ; \diamond, 75^{\circ} \mathrm{C}$

Figure 11- The changing of the immersed in $20 \%$ sucrose solution after dried samples $b$ values and drying time: $\triangle, 55^{\circ} \mathrm{C} ; \square, 65^{\circ} \mathrm{C} ; \diamond, 75^{\circ} \mathrm{C}$

\subsection{Kurutulmuş Trabzon hurmalarının raf ömrünün incelenmesi}

Renk değerleri açısından $80^{\circ} \mathrm{C}$ 'deki suya daldırılıp kurutulan Trabzon hurmalarının daha iyi olduğu sonucuna varılabilir. Bununla birlikte, kabin tipi kurutucuda aynı sürelerle kurutulmuş son üründe yapılan su aktivite tayinleri sonucunda, \% 20'lik şeker çözeltisine daldırılarak kurutulan Trabzon hurması örneklerinin su aktivite değerleri 0.60 olarak belirlenirken, $80{ }^{\circ} \mathrm{C}$ 'deki suya daldırılıp kurutulan Trabzon hurmalarının su aktivite değerleri ise 0.75 olarak ölçülmüştür. Bu sonuç, ozmotik ön kurutma tatbik edilmiş örneklerin sıcak suda bekletme şeklinde gerçekleştirilen ön işleme göre daha yüksek kuruma hızı sağladığını göstermektedir.

Polietilen poşet içerisine ambalajlanıp oda koşullarında muhafaza edilen kurutulmuş Trabzon hurmalarından $80^{\circ} \mathrm{C}$ 'deki suya daldırılıp kurutulan örneklerde 3 hafta sonunda mikrobiyal yönden bozulma belirlenmiştir. Fakat \% 20'lik şeker çözeltisine daldırılarak kurutulan örneklerde 6 ay boyunca her hangi bir mikrobiyal bozulma görülmemiştir.

\section{Sonuçlar}

Kurutma ortam sıcaklığı artışı kuruma hızında da artmayı sağlamış olmasına rağmen, tüketici tercihinde önemli bir role sahip olan kurutulmuş örneklerin renginde genel anlamda esmerleşmeye neden olduğu için yüksek sıcaklıklar önerilmemektedir.

Şeker çözeltisine (\% $\%$ 20’lik) daldırılarak gerçekleştirilen ozmotik ön kurutma işleminin de kurutulmuş Trabzon hurmalarının rengi üzerine olumlu bir etki yapmadığı saptanmıştır. Bununla birlikte, raf ömrü, kuruma hızı ve süresi açısından ozmotik ön kurutma uygulamasının avantajlı olduğu görülmüştür.

Yapılan duyusal analizler neticesinde de iki farklı ön işlem uygulanarak kurutulan örnekler arasında koku, lezzet, renk, çiğnenebilirlik ve genel beğeni açısından belirgin bir farkın bulunmayışı Trabzon hurmalarının kurutulmasında ozmotik ön kurutma işleminin belirtilen avantajları nedeniyle tercihte öne çıkmasını sağlamaktadır.

Yine yapılan duyusal değerlendirmelerde, panelistler kurutulmuş Trabzon hurmalarının fındık veya ceviz gibi gıdalarla beraber sevilerek tüketilebileceğini ifade etmişlerdir.

\begin{tabular}{|ll|}
\hline \multicolumn{2}{|l|}{ Kisaltmalar ve Semboller } \\
\hline$C$ & herhangi bir t anındaki renk parametresi değeri \\
$C_{0}$ & $\mathrm{t}=0$ anındaki renk parametresi değeri \\
$k$ & kinetik sabit $\left(\mathrm{h}^{-1}\right)$ \\
$t$ & kuruma zamanı (h) \\
$k_{o}$ & arrhenius sabiti veya frekans faktörü \\
$E_{a}$ & aktivasyon enerjisi $\left(\mathrm{kJ} \mathrm{mol}^{-1}\right)$ \\
$R$ & gaz sabiti $\left(8.314 \times 10^{-3} \mathrm{~kJ} \mathrm{~mol}^{-1} \mathrm{~K}^{-1}\right)$ \\
$T$ & sicaklık $(\mathrm{K})$ \\
\hline
\end{tabular}

\section{Kaynaklar}

Alibaş İ (2012). Asma yaprağının (Vitis vinifera L.) mikrodalga enerjisiyle kurutulması ve bazı kalite parametrelerinin belirlenmesi. Tarm Bilimleri Dergisi, 18: 43-53

Carcel J A, Garcia-Perez J V, Riera E \& Mulet A (2007). Influence of high-intensity ultrasound on drying kinetics of persimmon. Drying Technology, 25: 185-193 
Carcel J A, Garcia-Perez J V, Sanjuan N \& Mulet A(2010). Influence of pre-treatment and storage temperature on the evolution of the colour of dried persimmon. $L W T$ Food Science and Technology, 43: 1191-1196

Demiray E, Tulek Y \& Yilmaz Y (2013). Degradation kinetics of lycopene, $\beta$-carotene and ascorbic acid in tomatoes during hot air drying. LWT-Food Science and Technology, 50: (1), 172-176

Doymaz İ \& Pala M (2001). Daldırma çözeltisi kullanımının biber kuruma sürelerine etkisinin incelenmesi. Sigma Mühendislik ve Fen Bilimleri Dergisi 4: 44-50

Doymaz I (2012). Evaluation of some thin-layer drying models of persimmon slices (Diospyros kaki L.). Energy Conversion and Management, 56: 199-205

Hastürk F Ş, Ülger P, Aktaş T \& Orak H H (2012). Farklı ön işlemlerin ve vakum kurutma yönteminin domatesin kuruma karakteristikleri ve kalite kriterleri üzerine etkisi. Tekirdă̆ Ziraat Fakültesi Dergisi 9 (1): $15-25$

Holdsworth S M (1986). Advances in the dehydration of fruits and vegatables, Concentration and Drying of Foods (D. Mac Carthy ed. ), Elsevier App. Sci. Pub. Ltd., London, 293-303p

İspir A (2006). Kayısının ozmotik dehidrasyonu ve kurutmaya etkisi. Yüksek Lisans Tezi, Fırat Üniversitesi Fen Bilimleri Enstitüsü (Basılmamış), Elazı $\breve{g}$

Karkacier M (1998). Trabzon hurmasının (Diospyros kaki L.) kimyasal bileşimi üzerine araştırmalar. Doktora Tezi, Ankara Üniversitesi Fen Bilimleri Enstitüsü (Basılmamış), Ankara

Kaya A (2008). Kurutmada 1s1 ve kütle transferinin teorik ve deneysel olarak incelenmesi. Doktora Tezi, KTÜ Fen Bilimleri Enstitüsü (Basılmamış), Trabzon

Kitagawa H \& Glucina P G (1984). Persimmon Culture in New Zeland. DSIR Information Series No. 159, Science Information Publishing Centre, Wellington

Krokida M K \& Maroulis Z B (2000). The effect of drying methods on viscoelastic behaviour of dehydrate fruits and vegetables. International Journal of Food Science and Technology 35: 391-400

Luo Z (2006). Extending shelf-life of persimmon (Diospyros kaki L.) fruit by hot air treatment. European Food Research Technology 222: 149-154

Mutlu A \& Ergüneş G (2008). Tokat'ta güneş enerjili raflı kurutucu ile domates kurutma koşullarının belirlenmesi. Tarım Bilimleri Araştırma Dergisi 1(1): 61-68

Nicoleti J F, Silveira V, Telis-Romera J \& Telis V R N (2007). Influence of drying conditions on ascorbic acid during convective drying of whole persimmons. Drying Technology, 25: 891-899

Onur C (1990). Trabzon hurmas1. Derim (Özel Sayısı) 7(1): 4-47

Onur S (1985). Trabzon hurmas1. Derim 2(2): 38-42

Rastogi N K, Angersbach A \& Knorr D (2000). Evaluation of mass transfer mechanisms during osmotic treatment of plant materials, Journal of Food Science 65 (6):1016-1019

Sütyemez M \& Ergenoğlu F (2000). Kahramanmaraş Bölgesinde Trabzon hurmas1 (Diosypros kaki L.) seleksiyonu. Sütçü Imam Üniversitesi Fen ve Mühendislik Dergisi 3(1):51-57

Torreggiani D \& Bertolo G (2001). Osmotic pretreatments in fruit processing: chemical, physical and structural effects. Journal of Food Engineering 49: 247-253

Yağcıŏlu A(1996). Ürün İşleme Tekniğgi. Ege Üniversitesi Ziraat Fakültesi Yayınları No:536, İzmir

Yıldız E (2011). Farklı Trabzon hurması çeşitlerinde meyve verim ve kalitesi ile bitki besin maddeleri, karbonhidratlar ve meyve bileşimindeki bazı maddelerin mevsimsel değişimleri. Doktora Tezi, Mustafa Kemal Üniversitesi Fen Bilimleri Enstitüsü (Basılmamış), Hatay

Yonemori K, Sugiura A \& Yamada M (2000). Persimmon genetics and breeding. Plant Breeding Reviews 19(6): $191-225$ 